\title{
Modelo de gestión integral para fortalecer la industria agroalimentaria venezolana
}

\author{
Sánchez, Rebeca* \\ Najul, María Virginia** \\ Ferrara de Giner, Griselda*** \\ Ortega, Elizabeth****
}

\begin{abstract}
Resumen
El objetivo del presente artículo esta orientado a establecer un modelo de gestión orientado a fortalecer las empresas del sector agroalimentario venezolano, en la entrega de productos inocuos y de mejor calidad a sus consumidores, obtenidos bajo esquemas de producción eficientes y competitivos. En su construcción se identificaron, desarrollaron y articularon factores incorporados en el modelo, apoyados en el concepto de gestión integral y en las formas de actuación que han conducido a empresas nacionales y extranjeras a posicionarse en el mercado (qué, con qué, cómo, para qué o para quién hacen). La validez de los postulados fue verificada mediante análisis de correlación simple entre indicadores de desempeño empresarial y variables que revelan atención a la calidad, inocuidad, ambiente, seguridad e innovación tecnológica. Los resultados, obtenidos del procesamiento de información procedente de una muestra de 129 industrias del sector, señalan que la articulación de los factores producción segura, valoración del conocimiento e innovación tecnológica, así como políticas y acciones de responsabilidad social al concepto gestión integral, permite generar un modelo de gestión de adopción progresiva, que considerando la realidad del sector, facilita un mejoramiento continuo de su desempeño.
\end{abstract}

Palabras clave: Gestión Integral en la Agroindustria, Producción Segura, Seguridad Alimentaria Sostenible.

Recibido: 13-02-08. Aceptado: 25-06-09

* Profesora Investigadora del Departamento de Ingeniería Sanitaria y Ambiental de la Facultad de Ingeniería-Universidad Central de Venezuela. E-mail: rebecaucv@gmail.com

** Profesora Investigadora del Departamento de Ingeniería Sanitaria y Ambiental de la Facultad de Ingeniería-Universidad Central de Venezuela. E-mail: mvnajul@yahoo.es

*** Profesora Investigadora del Departamento de Ingeniería Sanitaria y Ambiental de la Facultad de Ingeniería-Universidad Central de Venezuela. E-mail: griferrara@cantv.net

**** Profesora Investigadora del Centro de Estudios para el Desarrollo - CENDES Universidad Central de Venezuela. E-mail: eliortega@cantv.net 
Modelo de gestión integral para fortalecer la industria agroalimentaria venezolana

Sánchez, Rebeca; Najul, María V.; Ferrara de Giner, Griselda y Ortega, Elizabeth

\title{
Integral management model to strengthen the agro-food industry
}

\begin{abstract}
This study proposes a management model to strengthen Venezuelan food industries in delivering safe and better quality products to consumers, using competitive and efficient production modes. Factors incorporated in the model were identified, developed and articulated, based on the concept of integral management and behaviour patterns that have led domestic and foreign firms to position themselves in the market (what, with what, how, for what or for whom is it done). Validity of the assumptions was verified by simple correlation analysis between corporate performance indicators and variables that reveal attention to quality, product safety, environment, safety and technological innovation. Results obtained after processing information from a sample of 129 industries indicate that a combination of safe production factors, valuation of knowledge and technological innovation, as well as social responsibility policies and actions for the integral management concept, make it possible to generate a progressively adopted management model that, considering the reality of the sector, can facilitate continuous performance improvement.
\end{abstract}

Key words: Integral management, safe production, sustainable food safety.

\section{Introducción}

La importancia de la industria agroalimentaria venezolana dentro de la estructura productiva del país, va más allá de lo económico. Factores tales como seguridad alimentaria y su incidencia en el desarrollo socioeconómico nacional, la convierten en un sector estratégico que requiere de un apoyo sostenido a través de la definición de políticas sectoriales específicas que ayuden a elevar el desempeño productivo de esta industria, así como la incorporación de estrategias de gestión empresarial que apuntalen su desarrollo sustentable ${ }^{1}$.
Cuando se analiza el desempeño de la actividad industrial calificada como exitosa, cualquiera sea su rubro, se observa un proceso evolutivo en sus estrategias de gestión, acompañado de un creciente conocimiento de las diferentes prácticas productivas, desarrollo de capacidades de aprendizaje tecnológico e incorporación de prácticas de gestión, que considera aspectos diferentes a los estrictamente económicos como son la protección del ambiente y la salud (Chavarría y Sepúlveda, 2001).

En este contexto, el propio sector productivo y las instituciones de apoyo ${ }^{2}$ han desarrollado técnicas, herramientas

1 La sostenibilidad es la clave para la creación de valor, es la forma de marcar la diferencia y de ayudar a mejorar la calidad de vida en el entorno de una organización. La sostenibilidad se desarrolla en tres espacios: económico, ambiental y social.

2 Centros de Investigación y Desarrollo, Asociaciones Empresariales, entre otros. 
y modelos de gestión que, aún cuando han demostrado su validez, no son fáciles de incorporar o implantar, a menos que se comprenda y asuma su importancia, formas de articulación, ventajas y oportunidades que ello ofrece.

Resultados preliminares del estudio sobre aprendizaje tecnológico y gestión integral (tecnología, calidad y ambiente) en la industria agroalimentaria venezolana ${ }^{3}$, revelan que un importante grupo de las empresas analizadas, especialmente las pequeñas, no han asumido que el desempeño de su organización puede mejorar significativamente en la medida que incorporen cambios en su actuación empresarial, enmarcado en lo que podría denominarse una visión holística del concepto de gestión integral.

Como contribución al planteamiento anterior, este trabajo pretende delinear un modelo de gestión integral donde estén articuladas las técnicas, herramientas y actividades que pueden ser utilizadas por empresas del sector agroalimentario, independientemente de su nivel de organización, tamaño u origen del capital, para responder en forma responsable a su compromiso de entregar oportunamente a los consumidores productos inocuos y de mejor calidad, obtenidos bajo esquemas de producción eficientes y competitivos. Adicionalmente se busca mostrar que la incorporación de la gestión del conocimiento, así como políticas y ac- ciones de responsabilidad social al concepto convencional de gestión integral, tradicionalmente enfocado hacia la gestión de la calidad y el ambiente en el sector agroindustrial, pueden significar mejoras sustanciales en su desempeño.

El desarrollo del modelo partió de la revisión y análisis de los factores que han inducido cambios $y$, en consecuencia, mejoras en el desempeño de la actividad productiva a nivel nacional e internacional. Ello permitió explorar formas de actuación que han conducido a las empresas a posicionarse en el mercado (qué, con qué, cómo, para qué o para quién hacen), y que a su vez han resultado en una producción sustentable y al servicio de la sociedad.

Bajo el marco de estos postulados de actuación y teniendo en cuenta el alcance e importancia de la adopción del concepto gestión integral, fueron analizados los resultados obtenidos en el levantamiento de información de 129 empresas de las diferentes ramas productivas de la agroindustria venezolana, distribuidas en seis regiones geográficas del país.

La validez de los postulados planteados en la estructuración del modelo fue verificada, al menos para el caso venezolano, mediante la correlación entre indicadores de desempeño empresarial y variables que revelan acciones dirigidas al manejo formal de los aspectos relacionados con la gestión integral, utilizando para ello el método de análisis de correla-

3 Proyecto de Investigación coordinado por el Centro de Estudios para el Desarrollo de la Universidad Central de Venezuela, donde las autoras son co-investigadoras y en cuyos resultados se enmarca este trabajo (Mercado et al., 2007). 
Modelo de gestión integral para fortalecer la industria agroalimentaria venezolana Sánchez, Rebeca; Najul, María V.; Ferrara de Giner, Griselda y Ortega, Elizabeth

ción de variables desarrollado por Testa $(2006)^{4}$.

De esta manera fueron identificados y desarrollados los factores a incorporar en el modelo, aceptando que el logro de un desempeño exitoso, en términos de posicionarse en los más altos niveles competitivos, respetando el compromiso de cumplir con los preceptos de la seguridad alimentaria, sustentabilidad productiva y contribución al desarrollo social, es un proceso evolutivo que debe considerar la realidad del entorno en el cual se desenvuelve la empresa y sus propias características. Es así como la propuesta del modelo para la Gestión Integral en la Industria de Alimentos, está basada en la articulación de tres conceptos considerados fundamentales: producción segura, valoración del conocimiento e innovación tecnológica y responsabilidad social corporativa, cuyo desarrollo constituye el cuerpo central de este trabajo. Finalmente se estructura y describe el modelo resultante con el propósito de facilitar su comprensión y por ende su implantación.

\section{La Gestión integral en el contexto del sector agroalimentario venezolano}

En el escenario socioeconómico actual, donde los cambios ocurren a gran ve- locidad, el sector empresarial, especialmente el de la pequeña y mediana empresa, está obligado a fortalecerse, perfeccionarse y enfocarse en los requerimientos y desafíos impuestos por el mismo. En respuesta se generan en su interior nuevos aprendizajes, que se traducen en cambios de política y operaciones, buscando mejorar su presencia en los mercados internacionalizados. Ello implica, entre otros, que la empresa debe tener la capacidad de percibir las señales indicadoras de cambios significativos en el entorno, así como controlar día a día las actividades de los actores, dentro y fuera de su sector (Palop y Vicente, 1999). Dicho de otra manera, requiere contar con modelos de gestión, ágiles y flexibles, que le faciliten mejorar su desempeño.

Al revisar los factores que han impulsado cambios significativos en las formas de actuación empresarial, se identifica que las firmas incrementan su competitividad cuando desarrollan procesos sistemáticos de mejoramiento de su gestión, con una clara orientación al medio en el que se desenvuelve y a sus clientes. Por otra parte, entendida la competitividad como la capacidad de la organización para mantener permanentemente ventajas que le permitan alcanzar, sostener y mejorar su posición en el mercado, las empresas deben ser entidades dinámicas, flexibles e insertas en un entorno

4 Testa (2006) desarrolló un método de análisis de correlación de variables medidas en escala nominal y dicotómica (si o no), donde determina un coeficiente coincidente con el conocido coeficiente de correlación, que permite establecer el grado de asociación que pueda existir entre variables seleccionadas. Valores igual o mayores a 0,26 son indicativos de buena correlación con un $99 \%$ de confiabilidad. 
también dinámico y con exigencias crecientes (Iglesias, 2002; Chavarría y Sepúlveda, 2001)

Sin duda, uno de los factores que tuvo mayor influencia en la necesidad de buscar nuevas formas de concebir la actividad empresarial, fue la inserción del concepto de desarrollo sostenible, entendido éste como una forma de desarrollo, que busca mantener o incrementar el bienestar humano y a la vez asegurar la equidad intra-generacional y la preservación de la reserva del capital total de la tierra -natural, humano y creado por el hombre-. En este sentido, la industria manufacturera, juega un papel primordial como transformadora del capital natural a través del capital humano y tecnologías, debiendo estar en el núcleo de cualquier estrategia de desarrollo sostenible (CEPAL, 1999).

Teniendo en cuenta estas consideraciones, los modelos de gestión sufren una importante modificación: además de reconocer la influencia de las circunstancias locales e internacionales en la organización, el tema ambiental deja de ser visto como un componente más a gestionar, para convertirse en eje transversal de la actuación empresarial. Un ejemplo de ello es el modelo propuesto por Najul et al. (2001), mostrado en el Diagrama 1, quienes partiendo de la concepción tradicional de gestión empresarial, descrita básicamente en términos económicos, tecnológicos y organizacionales, concluyen en un modelo triangular, donde los vértices representan los factores indicados que interactúan entre sí, afectados por las presiones del entorno local e internacional, e insertando la variable ambiental como eje transversal en todas sus actuaciones. Este modelo, que representa una primera versión de integración, fue posteriormente utilizado en el análisis de la industria química y petroquímica venezolana (Mercado y Testa, Editores, 2001).

Aún cuando el modelo parece abarcar todos los factores que influyen para lograr un desempeño aceptable en cualquier organización perteneciente al sector productivo, es necesario considerar las peculiaridades que representa el rubro al cual están dedicados, como por ejemplo las implicaciones asociadas al

\section{Diagrama 1}

\section{Inserción de la variable ambiental en la gestión empresarial.}

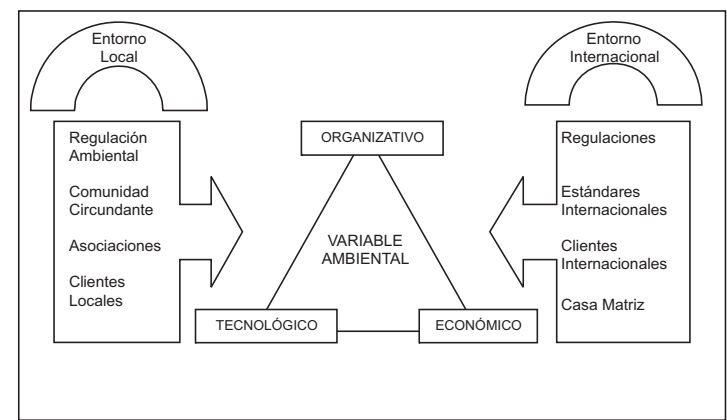

Fuente: Tomado de Najul et. al, 2001. 
Modelo de gestión integral para fortalecer la industria agroalimentaria venezolana Sánchez, Rebeca; Najul, María V.; Ferrara de Giner, Griselda y Ortega, Elizabeth

concepto de seguridad alimentaria, en el caso del sector agroalimentario.

Según la definición de la Organización de las Naciones Unidas para la Agricultura y la Alimentación (FAO, 1996), "existe seguridad alimentaria cuando todas las personas tienen en todo momento acceso físico y económico a suficientes alimentos inocuos y nutritivos para satisfacer sus necesidades alimentarias". Ello implica el cumplimiento de las siguientes condiciones: a) Una oferta y disponibilidad de alimentos adecuados b) La estabilidad de la oferta sin fluctuaciones ni escasez en función de la estación del año; c) El acceso a los alimentos o la capacidad para adquirirlos y d) La buena calidad e inocuidad de los alimentos.

Dadas estas características, para alcanzar niveles de competitividad, las empresas del sector agroalimentario deben incorporar estrategias de gestión orientadas al aseguramiento de la calidad e inocuidad de sus productos. No obstante diversos autores señalan que las empresas que no gestionen con carácter integral sus recursos, pueden quedar fuera del mercado a muy corto plazo, por lo cual deben realizar esfuerzos para mejorar el proceso productivo, sobre la base del tratamiento integrado de aspectos tales como: calidad, prevención de riesgos laborales y medio ambiente (Portillo, 2002). Ello implica que, en términos de producción, resulta imperativo incorporar estrategias de gestión que integren estos aspectos.

Entre los requisitos ineludibles para que la industria de alimentos desarrolle una genuina reconversión productiva, se encuentran la incorporación de criterios y sistemas de aseguramiento de la calidad e inocuidad de sus productos, de- biendo fomentar la creación o adopción de normas y fortalecer los correspondientes sistemas de gestión. Ambos constituyen elementos decisivos de una estrategia de desarrollo que estimule el cumplimiento de los acuerdos internacionales y exigencias del mercado local, cada vez más exigente en aspectos de higiene y sanidad agropecuaria.

Además de la atención a la calidad, toda empresa está en la obligación de atender los aspectos relacionados con el bienestar y seguridad de sus trabajadores, los cuales incluyen la evaluación global de las condiciones de trabajo, la respuesta ante las emergencias, la selección y uso de los equipos de protección personal, entre otras. La industria de alimentos contiene elementos de considerable riesgo, tales como equipos térmicos y mecánicos, así como el uso de sustancias químicas en las actividades de limpieza, que ameritan la consideración de estos aspectos.

Con respecto a la necesidad de gestionar los asuntos ambientales, conviene señalar que aun cuando el sector agroindustrial, suele considerarse de bajo impacto ambiental comparado con otros sectores industriales, en términos de la toxicidad de sus descargas, si se considera el volumen de residuos que puede generar, los requerimientos de adecuación para cumplir con los estándares establecidos en las normas y su ubicación con respecto a los cuerpos de agua superficiales, este sector puede adquirir una categoría tan importante como aquellos con mayor potencial de impacto ambiental (Chidiak y Murmis, 2003). De hecho, diversos organismos internacionales clasifican este sector como tipo B, 
caracterizado como de impacto intermedio sobre la salud y el ambiente y responsable de cerca del $50 \%$ de las descargas líquidas generadas en el País (World Bank, 2005).

Las estrategias de protección al ambiente han evolucionado desde el desarrollo de tecnologías de tratamiento de descargas, impuesto fundamentalmente por políticas de regulación, pasando por tecnologías de remediación, hasta el uso de tecnologías limpias, basadas en el logro de mayor eficiencia de los procesos productivos.

Para apoyar la gestión de estos factores - calidad-inocuidad, seguridad y ambiente (CISA) -, se han desarrollado diversidad de técnicas y herramientas, algunas de las cuales se resumen en el Cuadro 1. Sin embargo las mismas han surgido en forma separada, para el logro de objetivos variados e independientes, lo que trae como consecuencia que su incorporación y/o cumplimiento resulte onerosa y compleja, especialmente para las pequeñas y medianas organizaciones.

Aun cuando se conoce de la existencia de sistemas de gestión integral, que para las empresas pertenecientes al sector agroalimentario, se conciben como la articulación de un conjunto de estrategias y acciones destinadas a organizar y estructurar los procesos, mecanismos e infraestructura de la empresa a fin de asegurar la gestión exitosa de los factores CISA, el solo hecho de su implantación y certificación no garantiza el éxito. Es necesario desarrollar estrategias que faciliten a la organización entender por qué adopta el concepto de gestión integral y cómo puede avanzar en su implantación para avanzar en el mejoramiento de su desempeño.
Por otra parte, y como se discutirá más adelante, existe evidencia que facilitar el aprendizaje en la organización y valorar el aporte de las personas a su crecimiento y fortalecimiento, desarrollar capacidades de innovación tecnológica, así como asumir compromisos de ética y responsabilidad social tanto a lo interno como a lo externo de la organización, contribuyen al éxito de las organizaciones. Ello hace suponer que el concepto de gestión integral requiere ser ampliado $y$ tal como se ha mencionado anteriormente, debe incorporarse al modelo de gestión empresarial en forma articulada y considerando la realidad del entorno en el cual se desenvuelve la firma. En tal sentido la propuesta del modelo, objeto del presente estudio, se argumenta a partir del desarrollo de lo que se ha denominado niveles de aproximación a la gestión integral, los cuales abarcan tres factores centrales: producción segura, valoración del conocimiento e innovación tecnológica y responsabilidad social, incluyendo en la medida de lo posible, herramientas y estrategias para su incorporación.

\section{Producción segura: un primer nivel de aproximación a la gestión integral}

En la búsqueda de esquemas integradores que mejoren el desempeño de la industria de alimentos y faciliten el cumplimiento de los compromisos impuestos por los principios de seguridad alimentaria, así como las exigencias establecidas por las leyes venezolanas en materia de seguridad y protección ambiental, surge el concepto de producción segura, según el cual, la primera aproxi- 
Modelo de gestión integral para fortalecer la industria agroalimentaria venezolana Sánchez, Rebeca; Najul, María V.; Ferrara de Giner, Griselda y Ortega, Elizabeth

\section{Cuadro 1}

Instrumentos de Gestión Aplicables a la Industria Agroalimentaria en las Áreas Calidad - Inocuidad, Seguridad Industrial y Ambiente (CISA)

\begin{tabular}{|c|c|c|}
\hline Factor & Instrumento & Dirigido a \\
\hline \multirow{7}{*}{ 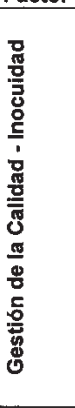 } & $\begin{array}{l}\text { Buenas Prácticas Agricolas (BPA), } \\
\text { Buenas Prácticas de Fabricación (BPF) } \\
\text { Buenas Prácticas de Transporte (BPT). }\end{array}$ & $\begin{array}{l}\text { Obtener alimentos con el menor riesgo para la salud de } \\
\text { los consumidores. En Venezuela se ha normado sobre } \\
\text { BPF y BPT. Normas de BPA en desarrollo }\end{array}$ \\
\hline & $\begin{array}{l}\text { Análisis de Riesgos y Control de Puntos Críticos. } \\
\text { Sistema HACCP (siglas en inglés) }\end{array}$ & Asegurar la inocuidad de los alimentos \\
\hline & Serie ISO 9000:2000 (Normas ISO*) & Gestión de la Calidad \\
\hline & $150^{*} 22000: 2005$ & Gestión de la Inocuidad \\
\hline & $\begin{array}{l}\text { Etiquetado (Norma General para el Rotulado de los } \\
\text { Alimentos. COVENIN. 2952:2001 - } 1^{\text {* }} \text {. Revisión) }\end{array}$ & Especificaciones sobre las características del alimento \\
\hline & Trazabilidad & $\begin{array}{l}\text { Rastrear materias primas y productos terminados, } \\
\text { desde su recepción hasta el primer punto de entrega. }\end{array}$ \\
\hline & $\begin{array}{l}\text { Elementos de reglamentación a nivel nacional } \\
\text { Registro Sanitarios } \\
\text { Permiso Sanitario }\end{array}$ & $\begin{array}{l}\text { Declarar el alimento apto para consumo humano } \\
\text { Autorizar el funcionamiento de establecimientos } \\
\text { destinados a la producción o fabricación de alimentos } \\
\text { para consumo humano }\end{array}$ \\
\hline \multirow{8}{*}{ 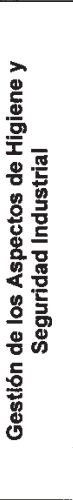 } & $\begin{array}{l}\text { La Ley Orgánica de Prevención, Condiciones y } \\
\text { Medio Ambiente de Trabajo - LOPCYMAT }\end{array}$ & $\begin{array}{l}\text { Garantizar a los trabajadores y trabajadoras } \\
\text { condiciones de seguridad, salud y bienestar }\end{array}$ \\
\hline & $\begin{array}{l}\text { Normas OHSAS } 18000 \text { (Occupational Health and } \\
\text { Safety Assessment Series) }\end{array}$ & $\begin{array}{l}\text { Facilitar la integración de los requisitos de seguridad y } \\
\text { salud ocupacional a los requisitos de calidad (ISO 9000) } \\
\text { y a los de administración ambiental (ISO 14000). }\end{array}$ \\
\hline & OHSAS 18001:1999 & $\begin{array}{l}\text { Referencial internacional para auditorias y certificación } \\
\text { por tercera parte }\end{array}$ \\
\hline & $\begin{array}{l}\text { Análisis de Riesgos y Operabilidad de los } \\
\text { Procesos - HAZOP, por sus siglas en inglés }\end{array}$ & $\begin{array}{l}\text { Identificar peligros potenciales y problemas } \\
\text { operacionales, así como sus consecuencias en la } \\
\text { instalación examinada. }\end{array}$ \\
\hline & $\begin{array}{l}\text { Método de Modo de Falla y Análisis de Efectos - } \\
\text { FMEA por sus siglas en ingles Failure Mode and } \\
\text { Effect Analysis }\end{array}$ & $\begin{array}{l}\text { Identificar modos de falla potenciales, determinar su } \\
\text { efecto e identificar acciones para atenuarlas }\end{array}$ \\
\hline & $\begin{array}{l}\text { Método de Análisis por Arboles de Falla - FTA por } \\
\text { sus siglas en inglés Fault Tree Analysis }\end{array}$ & Determinar tas causas que han producido accidentes \\
\hline & $\begin{array}{l}\text { Método de Análisis por Arboles de Eventos o } \\
\text { Sucesos - ETA por sus siglas en inglés Event Tree } \\
\text { Analysis }\end{array}$ & Evaluar las consecuencias de posibles accidentes \\
\hline & $\begin{array}{l}\text { FMECA - Análisis de Criticidad y Modos de Falla y } \\
\text { sus Efectos }\end{array}$ & $\begin{array}{l}\text { Identificar modos de falla críticas que pueden contribuir } \\
\text { o ser la causa de un accidente. }\end{array}$ \\
\hline \multirow{6}{*}{ 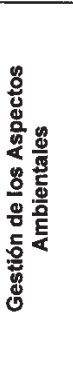 } & $\begin{array}{l}\text { Cuerpo normativo ambiental Venezolano: } \\
\text { Ley Orgánica del Ambiente, Ley de Aguas, Ley de } \\
\text { Residuos y Desechos, Decreto } 1.257 \text {, Decreto } N^{\circ} \\
883 \text { (actualmente en revisión) y Decreto } N^{\circ} 2.635 \text {. }\end{array}$ & $\begin{array}{l}\text { Marco legal y regulatorio venezolano en materia } \\
\text { ambiental. }\end{array}$ \\
\hline & Normas ISO 14000 & $\begin{array}{l}\text { Incorporar criterios de salvaguarda al ambiente a través } \\
\text { del desarrollo de sistemas de gestión ambiental. }\end{array}$ \\
\hline & Auditorias Ambientales - AA & $\begin{array}{l}\text { Verificar en forma objetiva información relativa a } \\
\text { desempeño ambiental. }\end{array}$ \\
\hline & Principios de Producción Más Limpia & $\begin{array}{l}\text { Incomorar métodos y técnicas orientados hacia la } \\
\text { minimización de las descargas }\end{array}$ \\
\hline & Etiquetado Ambiental - EA & $\begin{array}{l}\text { Certificar cumplimiento de criterios ambientales } \\
\text { establecidos de antemano, para la elaboración de un } \\
\text { producto }\end{array}$ \\
\hline & Evaluación del Ciclo de Vida - ECV & $\begin{array}{l}\text { Evaluar el impacto ambiental asociado a procesos, } \\
\text { productos y actividades. }\end{array}$ \\
\hline
\end{tabular}

Adaptado de: Asamblea Nacional (2005); Comisión del Codex Alimentarius (2005), Ministerio de Sanidad y Asistencia Social (1996), Rothery, B. (1996), Sánchez et al. (2001). 
mación a la gestión integral se logra cuando la organización incorpora de manera concertada, los aspectos relacionados con la eficiencia productiva y los factores CISA. Es decir, aquellas organizaciones que se avoquen a lograr una producción segura en los términos señalados, deberían mostrar un desempeño aceptable con respecto a los aspectos mencionados.

Aceptando como válido este planteamiento, sería conveniente contar con una herramienta o técnica cuya implantación apoye a la empresa en el logro de la seguridad microbiológica y toxicológica del producto, la seguridad de bienes y personas y la seguridad del proceso, como vía para la protección al ambiente, en forma integrada y con el uso eficiente de los recursos de la organización. Ello supone que las empresas, especialmente las pequeñas y medianas, concentren esfuerzos en lograr la producción segura, con el compromiso de avanzar más adelante pero con mayor facilidad, hacia la certificación de su gestión en los diferentes ámbitos de la gestión integral ${ }^{5}$.

La herramienta propuesta está basada en el trabajo desarrollado por Lovera (2006), quien con el propósito de desarrollar un instrumento para verificar el logro de la producción segura en una planta para elaboración de leche de larga duración, inspirado en el concepto de la Trazabilidad, aplicó algunas de las herramientas disponibles para el análisis y certificación en las áreas de CISA, identifi- cando que los factores, etapas y fases contempladas en ellas estaban diferenciadas sólo en el énfasis de su objetivo. Ello fue comprobado por el hecho de que el $74 \%$ del total de puntos de control identificados, eran producto de manera simultánea de los tres aspectos considerados en el concepto de producción segura y todos ellos estaban asociados a la seguridad del proceso, lo que, entre otros, refuerza la necesidad de promover prácticas preventivas, observadas fundamentalmente en la Buenas Prácticas de Manufactura, de carácter obligatorio en el caso venezolano.

Por otra parte, cuando se analiza el nivel de asociación o correlación entre las variables que dan señales de un desempeño aceptable en un significativo grupo de empresas (129) del sector agroindustrial venezolano con la existencia de estructuras organizativas formales para la gestión de los factores de CISA e incorporación de la innovación tecnológica como estrategia de gestión, se obtiene una importante correlación entre las variables seleccionadas, según muestra la Tabla 1.

En ella se observa que las empresas que cuentan con unidades formales de gestión de los diferentes factores han incorporado medidas preventivas y correctivas, que sin duda redundan en un mejor desempeño. Llama la atención la significativa correlación encontrada entre la disponibilidad de estructuras organizativas y la incorporación de la trazabilidad como instrumento de seguimiento y con-

$5 \quad$ Una vez que se pueda demostrar gestión exitosa de los factores involucrados en la producción segura el paso hacia la certificación debe ser mas sencillo. 
Modelo de gestión integral para fortalecer la industria agroalimentaria venezolana Sánchez, Rebeca; Najul, María V.; Ferrara de Giner, Griselda y Ortega, Elizabeth

Tabla 1

Niveles de Correlación Simple. Indicadores de Desempeño vs Factores Organizacionales y Adopción de la Trazabilidad - Sector Agroindustrial Venezolano

\begin{tabular}{|c|c|c|c|c|c|c|c|c|}
\hline & & & Inocuidad & Calidad & Ambiente & $\begin{array}{c}\text { Seguridad } \\
\text { industrial }\end{array}$ & I+D & $\begin{array}{c}\text { Ing y } \\
\text { Diseño }\end{array}$ \\
\hline & & & 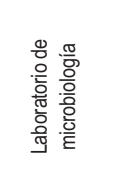 & 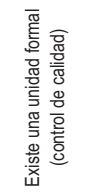 & 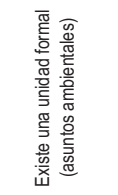 & 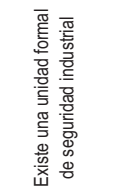 & 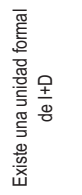 & 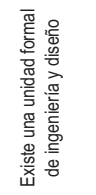 \\
\hline & & Permiso sanitario & 0,146 & $-0,008$ & $-0,174$ & $-0,042$ & $-0,126$ & $-0,113$ \\
\hline & & Registro sanitario & 0,245 & 0,292 & 0,078 & 0,149 & 0,104 & 0,163 \\
\hline & $\frac{\pi}{0} \ln$ & Implantó buenas prácticas de fabricación (BPF) & 0,269 & 0,512 & 0,334 & 0,501 & 0,340 & 0,293 \\
\hline & 言 In & Implantó HACCP & 0,292 & 0,375 & 0,428 & 0,436 & 0,488 & 0,334 \\
\hline & & Implantó buenas prácticas agrícolas (BPA) & 0,183 & 0,029 & 0,083 & 0,084 & 0,106 & 0,083 \\
\hline & $\frac{\pi}{\pi} \ln$ & Implantó otros sistemas & 0,077 & 0,203 & 0,215 & 0,333 & 0,385 & 0,280 \\
\hline$\stackrel{1}{0}$ & $\frac{\pi}{\pi} c$ & Certifiacación ISO 9000 & 0,154 & 0,201 & 0,259 & 0,301 & 0,272 & 0,337 \\
\hline 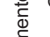 & & ISO 9000 en proceso de implantación & 0,111 & 0,092 & 0,218 & $-0,064$ & 0,165 & 0,127 \\
\hline$\frac{\underline{\underline{\xi}}}{\bar{\alpha}}$ & & Trazabilidad & 0,407 & 0,537 & 0,296 & 0,456 & 0,464 & 0,376 \\
\hline$\frac{1}{0}$ & & ISO 14000 en proceso de implantación & 0,109 & 0,189 & 0,401 & 0,197 & 0,261 & 0,106 \\
\hline 西 & & Su empresa está en el RASDA & 0,318 & 0,425 & 0,399 & 0,426 & 0,364 & 0,439 \\
\hline$\frac{\vec{n}}{2}$ & & Reducción del consumo de agua & 0,181 & 0,073 & 0,094 & 0,044 & 0,060 & 0,094 \\
\hline$\underline{\mathrm{g}}$ & & Segregación de desechos & 0,326 & 0,326 & 0,343 & 0,378 & 0,208 & 0,425 \\
\hline$\frac{\pi}{5}$ & & Colocación de trampas o tamices & 0,217 & 0,244 & 0,106 & 0,297 & 0,167 & 0,236 \\
\hline$\frac{0}{\frac{\pi}{2}}$ & & Control de fugas y derrames & 0,214 & 0,270 & 0,171 & 0,362 & 0,123 & 0,334 \\
\hline 5 & & Cambios en métodos de limpieza & 0,199 & 0,202 & 0,163 & 0,207 & 0,215 & 0,284 \\
\hline & & Cambios en manejo de desperdicios & 0,283 & 0,313 & 0,276 & 0,207 & 0,243 & 0,357 \\
\hline ळ & & Efluentes líquidos:Van a una planta de tratamiento & 0,411 & 0,381 & 0,292 & 0,480 & 0,252 & 0,377 \\
\hline 惫 & \& $S$ & Se procesan y comercializa el subproducto & 0,125 & 0,122 & 0,188 & 0,136 & 0,004 & 0,050 \\
\hline$\frac{0}{0}$ & $\frac{\omega}{\pi} S$ & Se procesan y reciclan & 0,064 & 0,090 & 0,158 & 0,143 & $-0,098$ & 0,158 \\
\hline ळ. & $\stackrel{\frac{\sigma}{0}}{-\frac{1}{0}} P$ & Planes para mejorar el manejo de los eff.líquidos & 0,425 & 0,316 & 0,236 & 0,365 & 0,088 & 0,322 \\
\hline$\frac{\overline{0}}{0}$ & 完 $\mathrm{E}$ & Emisiones gaseosas: van a un sistema de control & $-0,004$ & 0,154 & 0,438 & 0,262 & 0,084 & 0,323 \\
\hline$\frac{\pi}{\infty}$ & is $\mathrm{s}$ & Se procesan y comercializa el subproducto & $-0,034$ & 0,072 & 0,102 & 0,055 & $-0,085$ & 0,102 \\
\hline 읃 & 窎 $s$ & Se procesan y reciclan & $-0,034$ & 0,072 & 0,180 & 0,178 & 0,129 & 0,259 \\
\hline $\bar{\Xi}$ & \& $P$ & Planes para mejorar el manejo de las em. gaseosas & 0,169 & 0,194 & 0,368 & 0,301 & 0,180 & 0,368 \\
\hline 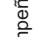 & & Desechos Sólidos: Van a una planta de tratamiento & 0,105 & 0,061 & 0,260 & 0,203 & 0,190 & 0,260 \\
\hline$\underset{\substack{\bar{E} \\
\infty}}{\bar{n}}$ & & Se procesan y comercializa el subproducto & $-0,080$ & 0,043 & 0,283 & 0,150 & 0,046 & 0,165 \\
\hline$\stackrel{\infty}{\Delta}$ & & Se procesan y reciclan & $-0,080$ & 0,043 & 0,047 & 0,104 & 0,100 & 0,283 \\
\hline 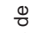 & & Planes para mejorar el manejo de los Des. Sólidos & 0,099 & 0,278 & 0,360 & 0,405 & 0,128 & 0,264 \\
\hline$\Longleftrightarrow$ & & Desechos peligrosos: Almacenados bajo condiciones seguras & 0,183 & 0,315 & 0,288 & 0,472 & 0,207 & 0,399 \\
\hline$\pi$ & & Se tratan internamente & 0,028 & 0,092 & 0,262 & 0,138 & $-0,072$ & 0,100 \\
\hline 弟 & & Se tratan a través de terceros & 0,155 & 0,266 & 0,260 & 0,399 & 0,417 & 0,384 \\
\hline $\begin{array}{l}= \\
0\end{array}$ & & Otro tipo de manejo & 0,087 & 0,113 & 0,057 & 0,170 & 0,032 & 0,322 \\
\hline 气 & & Planes para mejorar el manejo de los Des. Pelig. & 0,125 & 0,179 & 0,188 & 0,298 & 0,380 & 0,394 \\
\hline (으 & & Accidentes en los últimos cuatro años & 0,229 & 0,487 & 0,267 & 0,496 & 0,246 & $\overline{0,348}$ \\
\hline & 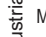 & Manuales de proced. en todas las fases del proceso & 0,162 & 0,269 & 0,289 & 0,452 & 0,377 & 0,333 \\
\hline & 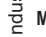 & Medidas para la prev. de riesgos: Monitoreo & 0,148 & 0,225 & 0,252 & 0,412 & 0,335 & 0,414 \\
\hline & $\frac{\pi}{\pi} P$ & Puntos de control & 0,175 & 0,282 & 0,352 & 0,394 & 0,405 & 0,352 \\
\hline & $\frac{\pi}{0} s$ & Supervisión & 0,209 & 0,369 & 0,195 & 0,308 & 0,152 & 0,145 \\
\hline & క్త్రN $N$ & Mantenimiento & 0,123 & 0,270 & 0,110 & 0,340 & 0,219 & 0,201 \\
\hline & ${ }^{\infty} 0$ & Otras medidas & 0,153 & 0,107 & $-0,006$ & 0,111 & 0,086 & 0,209 \\
\hline
\end{tabular}

Fuente: Elaboración propia basada en el análisis de correlación realizado por Testa (2006). 
trol del producto. Lo anterior sugiere que el factor común en la actuación en pro de un desempeño integral aceptable, lo constituye el registro, seguimiento y control de la información generada en cada una de las áreas.

De lo expuesto hasta el momento se concluye que la producción segura contribuye a mejorar la competitividad de las empresas mientras que la trazabilidad constituye una manera de abordar el seguimiento, registro y control de la calidad e inocuidad, seguridad industrial, seguridad del proceso e impacto ambiental, de manera integral y no parcelada, destacando el ahorro en recursos y tiempos de aplicación. El Diagrama 2 esquematiza esta idea.

\section{Valoración del conocimiento e innovación tecnológica, una oportunidad de integración}

Para lograr una producción segura en los términos descritos, es necesario que las empresas del sector agroalimentario desarrollen capacidades que les permitan gestionar eficientemente los aspectos organizacionales, tecnológicos y económicos, asegurando entre otros, capacidad de respuesta ante los cambios que puedan resultar del surgimiento de nuevos conocimientos, en torno a factores relacionados con la inocuidad y calidad de sus productos, el impacto ambiental ocasionado por sus actividades u otras exigencias del mercado. Considerando además que requiere desenvolverse en un medio intensivo en conocimientos, altamente competitivo y donde cada vez resulta más importante explotar mercados globales.

Desarrollar tales capacidades implica, entre otros, incorporar al conocimiento como pieza clave del éxito de la empresa, lo cual puede lograrse promoviendo estrategias de gestión centradas en el aprendizaje, los flujos de información entre la empresa y su entorno en tiempo real y paralelo, así como exaltando el conocimiento desarrollado en lo interno de la organización (OECD, 2003).

Con relación a los dos primeros aspectos, en el campo empresarial se ha introducido el concepto de inteligencia para la acción, definida como un proceso con-

\section{Diagrama 2}

Integración de las herramientas o instrumentos de gestión

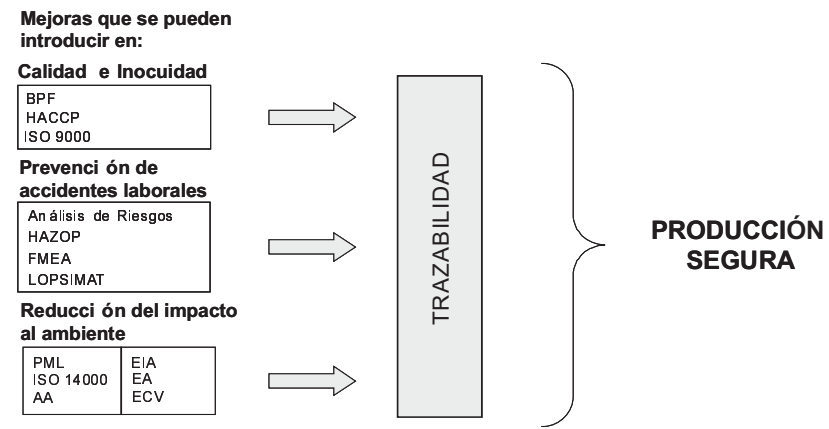

Fuente: Elaboración propia. 
Modelo de gestión integral para fortalecer la industria agroalimentaria venezolana Sánchez, Rebeca; Najul, María V.; Ferrara de Giner, Griselda y Ortega, Elizabeth

tinuo de transformación de datos, información y conocimiento del entorno, en un producto inteligente para la acción (Actionable Intelligence $)^{6}$ que pretende, además de revisar el entorno con miras a obtener información sobre las oportunidades y amenazas que puedan existir para la organización, determinar qué información es la de mayor valor y por lo tanto es necesario obtener, qué medios utilizar, cómo trasmitirla y sobre todo, cómo generar oportunamente un resultado incorporable a la toma de decisiones de la organización. También funciona como un sistema de alerta temprana que actúa como un radar, que ejerce un constante y amplio rastreo, que localiza y organiza colectivamente los esfuerzos individuales, sobre acontecimientos que pueden ser relevantes para la empresa (Palop y Vicente, 1999).

Este entorno está conformado por el mercado, el sistema científico-técnico (universidades, centros de investigación), el sistema mediador (consultores, incubadoras, eventos industriales y comerciales, literatura disponible) y entes públicos (oficinas de patentes, organismos de regulación, promotores financieros).

En el marco de las actividades organizacionales, aparece la Inteligencia Competitiva y Tecnológica (ICyT), entendida como el proceso enfocado a monitorear el ambiente competitivo y tecnológico de una organización (empresa, universidad, organismo), con la finalidad de que los ejecutivos (niveles altos y medios) tomen decisiones más acertadas, sobre todo las relacionadas con el mercado, innovación, diseño de productos, e investigación y desarrollo (I+D), y con la implementación de tácticas que forman parte de las estrategias a largo plazo. La ICyT se lleva a cabo en organizaciones de todos los tamaños a través de un proceso continuo y sistemático, que implica la recolección legal y ética de información, análisis con conclusiones relevantes, y la obtención y difusión controlada de resultados útiles (por ejemplo, las oportunidades y amenazas del entorno externo) para los procesos de planeación estratégica (SCIP, 2001).

De lo anterior se deduce que la inteligencia competitiva está orientada a comprender el mercado, identificar cuáles de las numerosas fuerzas presentes en el entorno son las de mayor importancia, y permitir un profundo entendimiento de las metas, objetivos y planes que persigue la organización. Por su parte, la inteligencia tecnológica se concentra en el seguimiento de las tecnologías, su evaluación y pronóstico, evaluación de competidores, vendedores, proveedores, y colaboradores, así como al seguimiento y análisis de tendencias de mercado, sociales, y reguladores, con impacto en las actividades científicas y tecnológicas. Para llevar adelante las actividades de ICyT, es necesario que las organizaciones cuenten con sistemas de gestión de la información que les permitan transformar datos en un producto inteligente (conocimiento útil y con valor estratégico), y que brinden las condiciones necesarias para que exista un flujo continuo 
de conocimiento en toda la estructura organizativa.

Retornando a los factores que, de acuerdo a las tendencias observadas en el campo de la gestión empresarial, podrían contribuir al desarrollo de capacidades para mejorar el desempeño de las organizaciones, y estrechamente relacionado con lo anterior, destaca la necesidad que tiene la empresa de hoy de aprender a desarrollar su capital intelectual para conseguir ventajas sobre sus competidores. Entendido este capital como la suma y sinergia de todos los conocimientos que reúne la organización, toda la experiencia acumulada en sus integrantes, todo lo que ha conseguido en términos de relaciones, procesos, descubrimientos, innovaciones, presencia en el mercado e influencia en la comunidad (Miller, 2002; Escorsa, et al., 2001; Herring, 1992).

Se incorpora aquí un elemento adicional, pero no menos importante, como es la necesidad de situar a los profesionales de la empresa en particular y a todos sus integrantes en general, junto a los procesos, en el centro de los activos de la organización ${ }^{7}$, como principal elemento de diferenciación en el mercado. Se reconoce la necesidad de lograr que las personas se interesen en invertir su talento en la organización, con mayor nivel de participación e implicación. Se trata de implantar sistemas de gestión del talento, lo cual va mucho más allá de promover la seguridad y bienestar del capital humano con el que cuenta la organización.

En síntesis, es posible afirmar que, de acuerdo a los planteamientos anteriores, un factor fundamental para que las empresas del sector agroindustrial ${ }^{8}$ avancen hacia un desempeño exitoso, lo constituye la incorporación de estrategias dirigidas a valorar la importancia de la información y del conocimiento, promoviéndolo, estructurándolo y haciéndolo operativo o válido para la empresa. En otras palabras, facilitar el aprendizaje en la organización y valorar el aporte de las personas. Este concepto se ilustra en el Diagrama 3.

Existe una estrecha relación entre la innovación tecnológica y la capacidad de la empresa para generar, capturar y valorar la información y el conocimiento.

En términos generales, la tecnología se define como el conocimiento que la empresa tiene sobre cierta área de la ciencia o ingeniería y que le permite obtener productos o servicios y comercializarlo (Roussel et al., 1991). La gestión tecnológica es la actividad organizacional mediante la cual se define e implanta la tecnología, para lograr objetivos y metas del negocio en términos de calidad, efec-

7 El conocimiento organizativo se ha convertido en "el recurso" por excelencia. Algunas razones son: no comercializable, desarrollado y acumulado dentro de la empresa, surge a partir de las habilidades y aprendizaje organizativo, es inmóvil y está vinculado a la empresa, El conocimiento organizativo se mide a través del capital intelectual de la organización (De La Fuente, 2003).

8 El planteamiento se considera válido para cualquier organización, independientemente de su especialidad. 
Modelo de gestión integral para fortalecer la industria agroalimentaria venezolana Sánchez, Rebeca; Najul, María V.; Ferrara de Giner, Griselda y Ortega, Elizabeth

\section{Diagrama 3 Integración de estrategias para la valoración de la información y el conocimiento}
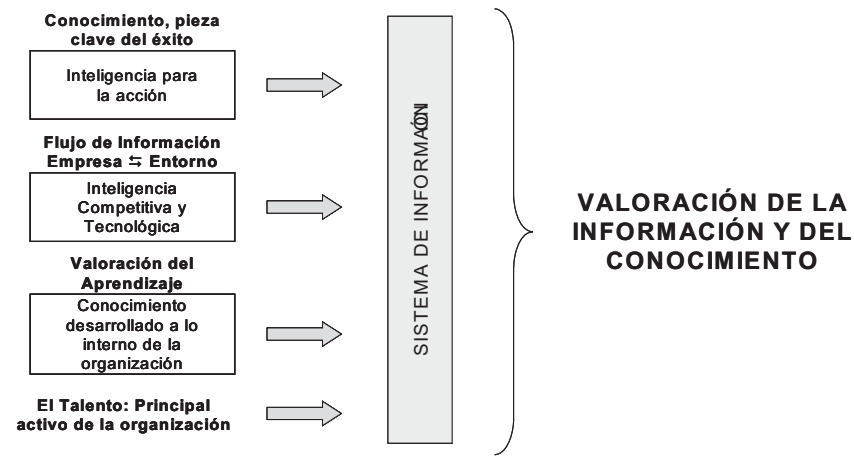

Fuente: Elaboración propia.

tividad, adición de valor y competitividad. Adicionalmente se reconoce que el éxito de la organización se relaciona en gran medida con el grado de asimilación y dominio de la tecnología en la cual se basa su negocio, que es el grado de conocimiento y entendimiento que sus empleados logran acerca de ella y depende, en buena parte, del nivel de formación del personal, de la importancia que se de a la capacitación y entrenamiento, de la actitud de la gerencia hacia la aceptación de nuevas ideas y de los esquemas de comunicación que se usan en la empresa. En esencia la asimilación de la tecnología es un proceso de transferencia de conocimientos.

Freeman (1998), sostiene que la tecnología ha dejado de ser considerada una variable externa, para convertirse en el resultado de las decisiones de las empresas que, utilizando los conocimientos cientificos disponibles, invierten en actividades de I+D para conseguir desarrollar innovaciones comercializables en el mercado. En consecuencia, no es posible desvincular el desempeño exitoso de las empresas y su capacidad para introducir el proceso innovador en sus estrategias de actuación, entendido como un proceso interactivo en el que la empresa, además de adquirir conocimientos mediante su propia experiencia en los procesos de diseño, desarrollo, producción y comercialización, aprende constantemente de sus relaciones con diversas fuentes externas, entre las que se encuentran los proveedores, los consumidores y diversas instituciones, tales como universidades, centros de investigación, consultores o las propias empresas competidoras.

Las actividades de I+D y el diseño creativo constituyen un capital intangible para el desarrollo de nuevos productos o procesos. Este capital intangible supone, a su vez, un incentivo para la inversión en capital físico, dado que la existencia de una nueva tecnología estimula la adquisición de nuevos equipos. La inversión, por su lado, estimula la realización de más I+D y aprendizaje creativo. De una manera similar, mejoras en la calidad del traba- 
jo -conocimientos, habilidades y formación- son tanto una exigencia como un estímulo para el cambio tecnológico y constituyen, al mismo tiempo, otra forma de inversión: capital humano. Todo este proceso, con múltiples interacciones, se caracteriza por el papel de la tecnología que, al contrario de lo que sucede con la inversión en capital físico y humano, cuya contribución a la producción es más directa, tiene un efecto multiplicador: una "externalidad", que contribuye a que las tres piezas interaccionen, estimulando la innovación y, en definitiva, la competitividad de las empresas y el crecimiento del negocio.

De lo anterior se desprende que para desarrollar capacidades de innovación tecnológica es necesario estimular la actividad propiamente dicha, incorporando la valoración de la información y del conocimiento como estrategia de gestión, tal como se esquematiza en el Diagrama 4.

Con el propósito de revisar la relación existente entre las variables que evi- dencian un desempeño aceptable en los factores de gestión integral basado en el concepto de producción segura, y aquellas que revelan innovación tecnológica en el sector agroindustrial venezolano existencia de unidades formales de I+D, ejecución de modificaciones al proceso y automatización y control-, se elaboró la Tabla 2.

Una vez más lo resultados muestran la significativa correlación encontrada, confirmando la conveniencia de orientar las estrategias de gestión hacia la incorporación de los conceptos valoración de la información y del conocimiento, e innovación tecnológica. Ello constituye una oportunidad para que las empresas de cualquier sector, se consoliden como organizaciones innovadoras y en consecuencia mejoren su competitividad y sustentabilidad. La Figura 1 resume la integración de las actividades de valoración del conocimiento e innovación tecnológica para el logro de ventajas competitivas.

\section{Integración de estrategias para estimular la Innovación Tecnológica \\ Diagrama 4}

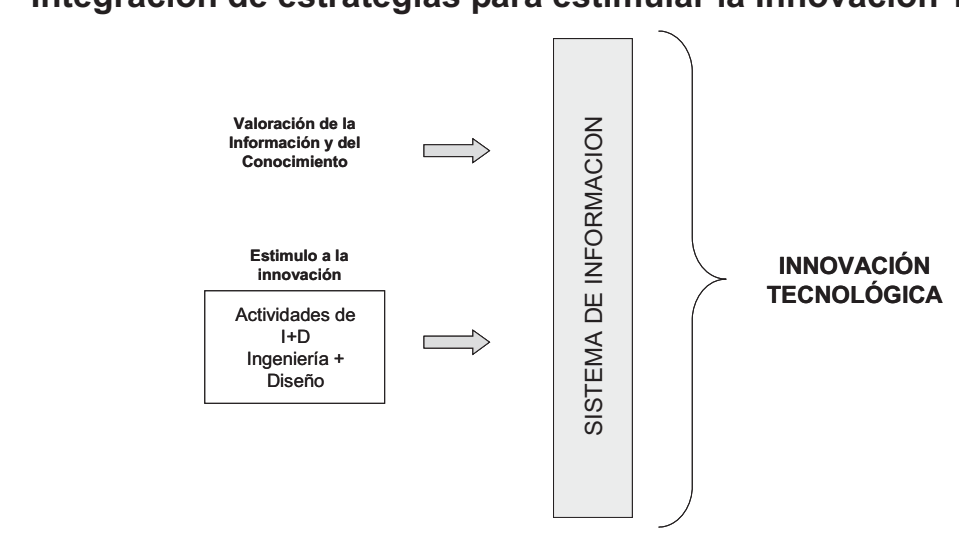

Fuente: Elaboración propia. 
Modelo de gestión integral para fortalecer la industria agroalimentaria venezolana Sánchez, Rebeca; Najul, María V.; Ferrara de Giner, Griselda y Ortega, Elizabeth

Tabla 2

Niveles de Correlación Simple. Indicadores de Desempeño vs Factores Reveladores de Innovación Tecnológica - Sector Agroindustrial Venezolano

\begin{tabular}{|c|c|c|c|c|c|c|c|c|c|c|c|c|c|}
\hline & & & & & & & ue & . & & n T & 10 & & \\
\hline & & & 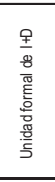 & 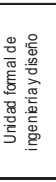 & 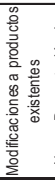 & 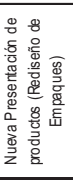 & 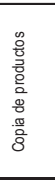 & 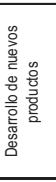 & 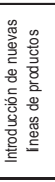 & 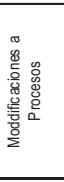 & 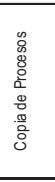 & 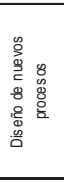 & 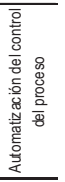 \\
\hline & & Permiso sanitario & $-0,126$ & $-0,113$ & $-0,097$ & $-0,078$ & 0,008 & $-0,048$ & 0,024 & $-0,056$ & $-0,061$ & $-0,046$ & $\overline{0,053}$ \\
\hline & & Registro sanitario & 0,104 & 0,163 & 0,035 & 0,294 & 0,102 & 0,097 & 0,138 & 0,178 & $-0,064$ & $-0,065$ & 0,127 \\
\hline & $\frac{\pi}{2}$ & Implantó buenas prácticas de fabricación (BPF) & 0,340 & 0,293 & 0,213 & 0,297 & 0,051 & 0,349 & 0,256 & 0,400 & $-0,002$ & 0,232 & 0,359 \\
\hline & ప్̉ & Implantó HACCP & 0,488 & 0,334 & 0,252 & 0,322 & 0,057 & 0,382 & 0,253 & 0,279 & $-0,083$ & 0,195 & 0,283 \\
\hline & $\subseteq$ & Implantó buenas prácticas agricolas (BPA) & 0,106 & 0,083 & 0,084 & 0,103 & $-0,081$ & 0,096 & $-0,015$ & 0,120 & $-0,103$ & 0,087 & 0,142 \\
\hline & $\frac{\pi}{\pi}$ & Implantó otros sistemas & 0,385 & 0,280 & 0,182 & 0,114 & 0,001 & 0,126 & 0,155 & 0,237 & 0,037 & 0,241 & 0,161 \\
\hline$\stackrel{\infty}{0}$ & $\frac{\bar{\pi}}{\pi}$ & Certifiacación ISO 9000 & 0,272 & 0,337 & 0,178 & 0,212 & 0,043 & 0,011 & 0,135 & 0,226 & 0,099 & 0,249 & 0,245 \\
\hline$\stackrel{\llcorner}{\Phi}$ & & ISO 9000en proceso de implantación & 0,165 & 0,127 & 0,142 & 0,119 & 0,256 & 0,192 & 0,253 & 0,119 & 0,021 & 0,250 & 0,165 \\
\hline$\varangle$ & & Trazabilidad & 0,464 & 0,376 & 0,266 & 0,385 & 0,077 & 0,383 & 0,399 & 0,287 & $-0,019$ & 0,287 & 0,367 \\
\hline 8 & & ISO 14000 en proceso de implantación & 0,261 & 0,106 & 0,197 & 0,253 & $-0,018$ & 0,181 & 0,176 & 0,086 & $-0,138$ & $-0,133$ & 0,163 \\
\hline 㩊 & & Su empresa está en el RASDA & 0,364 & 0,439 & 0,107 & 0,197 & 0,011 & 0,131 & 0,098 & 0,347 & 0,002 & 0,199 & 0,347 \\
\hline$\frac{\omega}{\partial}$ & & Reducción del consumo de agua & 0,060 & 0,094 & $-0,019$ & 0,026 & $-0,107$ & 0,004 & $-0,016$ & 0,190 & $-0,120$ & 0,145 & 0,271 \\
\hline$\frac{5}{\underline{\sigma}}$ & & Segregación de desechos & 0,208 & 0,425 & 0,249 & 0,328 & $-0,038$ & 0,248 & 0,108 & 0,376 & 0,019 & 0,158 & 0,339 \\
\hline$\frac{1}{c}$ & & Colocación de trampas o tamices & 0,167 & 0,236 & 0,161 & 0,134 & $-0,055$ & 0,156 & 0,137 & 0,244 & 0,086 & 0,126 & 0,227 \\
\hline$\frac{\pi}{\sqrt{2}}$ & & Control de fugas y derrames & 0,123 & 0,334 & 0,137 & 0,207 & 0,082 & 0,166 & 0,223 & 0,388 & 0,014 & 0,220 & 0,449 \\
\hline 拨 & & Cambios en métodos de limpieza & 0,215 & 0,284 & 0,048 & 0,179 & $-0,007$ & 0,157 & 0,075 & 0,332 & 0,031 & 0,124 & 0,209 \\
\hline$\underline{E}$ & & Cambios en manejo de desperdicios & 0,243 & 0,357 & 0,255 & 0,289 & $-0,073$ & 0,203 & 0,285 & 0,248 & $-0,076$ & 0,221 & 0,318 \\
\hline & & Efluentes liquidos: Van a una planta de tratamiento & 0,252 & 0,377 & 0,179 & 0,273 & $-0,133$ & 0,299 & 0,125 & 0,416 & 0,014 & 0,131 & 0,233 \\
\hline 0 & & Se procesan y comercializa el subproducto & 0,004 & 0,050 & 0,136 & 0,136 & $-0,089$ & 0,193 & $-0,006$ & 0,155 & 0,058 & 0,109 & 0,070 \\
\hline$\frac{0}{0}$ & $\frac{0}{\frac{\pi}{n g}}$ & Se procesan y reciclan & $-0,098$ & 0,158 & 0,025 & 0,042 & $-0,081$ & $-0,021$ & 0,044 & 0,120 & 0,084 & 0,087 & 0,201 \\
\hline \& & 岕 & Planes para mejorar el manejo de los effl.iquidos & 0,088 & 0,322 & 0,093 & 0,134 & $-0,055$ & 0,122 & 0,034 & 0,348 & 0,032 & 0,203 & 0,329 \\
\hline$\frac{\bar{o}}{\tilde{c}}$ & है & Emisiones gaseosas: van a un sistema de control & 0,084 & 0,323 & 0,035 & 0,171 & 0,064 & 0,062 & 0,107 & 0,195 & 0,217 & 0,213 & 0,315 \\
\hline$\frac{10}{0}$ & 8 & Se procesan y comercializa el subproducto & $-0,085$ & 0,102 & 0,055 & 0,021 & 0,043 & $-0,050$ & 0,135 & 0,164 & 0,197 & 0,110 & 0,245 \\
\hline$\stackrel{\underline{c}}{c}$ & 莺 & Se procesan y reciclan & 0,129 & 0,259 & 0,116 & 0,085 & 0,043 & 0,073 & 0,135 & 0,164 & 0,295 & 0,249 & 0,245 \\
\hline$\stackrel{\bar{\omega}}{\stackrel{0}{c}}$ & & Planes para mejorar el manejo de las em. gaseosas & 0,180 & 0,368 & 0,063 & 0,215 & 0,018 & 0,024 & 0,055 & 0,244 & 0,142 & 0,237 & 0,320 \\
\hline ळ & & Desechos Sólidos: Van a una planta de tratamiento & 0,190 & 0,260 & 0,105 & 0,078 & $-0,101$ & 0,096 & 0,129 & 0,150 & $-0,051$ & 0,054 & 0,178 \\
\hline$\varepsilon$ & & Se procesan y comercializa el subproducto & 0,046 & 0,165 & 0,104 & $-0,034$ & 0,072 & $-0,051$ & $-0,011$ & 0,086 & 0,083 & 0,128 & 0,116 \\
\hline هั & & Se procesan y reciclan & 0,100 & 0,283 & $-0,035$ & 0,110 & 0,072 & $-0,005$ & 0,083 & 0,086 & 0,157 & 0,180 & 0,163 \\
\hline$\frac{1}{0}$ & & Planes para mejorar el manejo de los Des. Sólidos & 0,128 & 0,264 & 0,141 & 0,145 & $-0,150$ & 0,055 & 0,063 & 0,216 & $-0,012$ & 0,179 & 0,105 \\
\hline$\infty$ & & Desechos peligrosos : Almacenados bajo condiciones seguras & 0,207 & 0,399 & 0,124 & 0,287 & $-0,035$ & 0,229 & 0,240 & 0,266 & 0,055 & 0,129 & 0,210 \\
\hline 윰 & & Se tratan internamente & $-0,072$ & 0,100 & 0,011 & 0,097 & $-0,035$ & 0,118 & 0,019 & $-0,025$ & $-0,045$ & 0,066 & 0,112 \\
\hline & & Se tratan a través de terceros & 0,417 & 0,384 & 0,154 & 0,230 & $-0,006$ & 0,243 & 0,228 & 0,250 & $-0,051$ & 0,054 & 0,178 \\
\hline & & Otro tipo de manejo & 0,032 & 0,322 & 0,066 & 0,012 & $-0,043$ & 0,041 & 0,181 & 0,127 & 0,111 & 0,140 & 0,138 \\
\hline 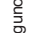 & & Planes para mejorar el manejo de los Des. Pelig. & 0,380 & 0,394 & 0,190 & 0,136 & $-0,089$ & 0,193 & 0,103 & 0,210 & $-0,028$ & 0,109 & 0,233 \\
\hline « & & Accidentes en los últimos cuatro años & 0,246 & 0,348 & 0,241 & 0,338 & $-0,064$ & 0,254 & 0,251 & 0,534 & 0,161 & 0,250 & 0,265 \\
\hline & 密 & Manuales de proced. en todas las fases del proceso & 0,377 & 0,333 & 0,315 & 0,227 & 0,082 & 0,312 & 0,153 & 0,302 & 0,038 & 0,214 & 0,213 \\
\hline & 혿 & Medidas para la prev. de riesgos: Monitoreo & 0,335 & 0,414 & 0,158 & 0,265 & 0,059 & 0,269 & 0,313 & 0,287 & 0,137 & 0,313 & 0,323 \\
\hline & $\bar{\sigma}$ & Puntos de control & 0,405 & 0,352 & 0,264 & 0,250 & 0,091 & 0,266 & 0,187 & 0,298 & 0,180 & 0,350 & 0,359 \\
\hline & : & Supervisión & 0,152 & 0,145 & 0,191 & 0,217 & $-0,012$ & 0,271 & 0,200 & 0,221 & 0,054 & 0,219 & 0,139 \\
\hline & ह & Mantenimiento & 0,219 & 0,201 & 0,197 & 0,200 & $-0,041$ & 0,186 & 0,196 & 0,267 & 0,099 & 0,205 & 0,466 \\
\hline & & Otras medidas & 0,086 & 0,209 & 0,111 & 0,062 & 0,133 & 0,062 & 0,132 & 0,138 & 0,070 & 0,256 & 0,104 \\
\hline
\end{tabular}

Fuente: Elaboración propia basada en el análisis de correlación realizado por Testa (2006). 


\section{Figura 1 \\ Integración de las actividades de valoración del conocimiento e innovación tecnológica para el logro de ventajas competitivas}

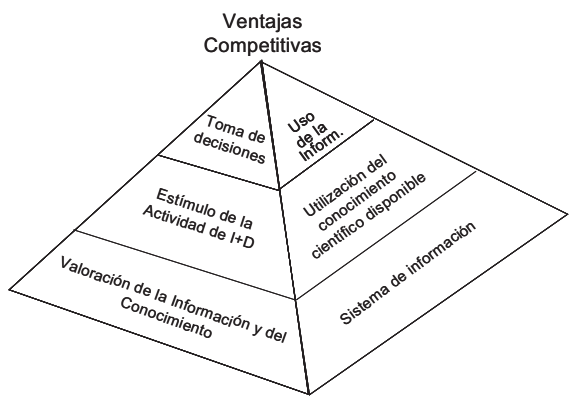

Fuente: Elaboración propia.

\section{Responsabilidad social, otro factor a incorporar en el modelo de gestión integral}

La responsabilidad social de la organización, conocida en el ámbito empresarial como responsabilidad social corporativa (RSC), se concibe como la respuesta que debe dar el sector productivo a una nueva actitud del público frente a la actividad empresarial, que se traduce en mayores exigencias para que las empresas operen según códigos y estándares de comportamiento responsable, asumiendo la responsabilidad de los impactos que genera, creando con ello valor para sus accionistas y la sociedad a través de buenas prácticas. Se parte del principio que la economía global no sólo es un fenómeno comercial o financiero, sino que contiene dimensiones de transformación social de mayor alcance. A través de la RSC las empresas se conciencian del impacto de sus acciones y expre- san su compromiso de contribuir al desarrollo económico y mejorar la calidad de vida de los trabajadores y sus familias, de la comunidad donde actúan y de la sociedad en su conjunto (Correa et al., 2004).

En la medida en que las empresas se percataron de que la puesta en marcha de políticas y acciones de RSC contribuían a la creación de un mayor valor social de la empresa y constituían una fuente de beneficios en términos de reputación e imagen corporativa, lo que a su vez conducía a la reducción del riesgo de oposición pública contra sus operaciones, conservación de los clientes y facilidad de ingreso a nuevos mercados con mayores exigencias, la RSC se convierte en una forma de hacer negocios, mas que una simple filantropía, que toma en cuenta los efectos sociales, ambientales y económicos de la acción empresarial, integrando en ella el respeto por los valores éticos, las personas, las comunidades y el medio ambiente.

La necesidad de que las empresas tengan en cuenta criterios de ética y de responsabilidad social en sus actuaciones diarias parece estar ampliamente aceptado. La RSC debe tomar en cuenta todos los grupos de interés: tanto los dividendos y ganancias de los accionistas, como la satisfacción de los consumidores, transparencia fiscal frente a los poderes públicos y la sociedad, remuneración del personal y desarrollo de los recursos humanos (Núñez, 2003).

Entre los factores que han contribuido a esta forma de entender la actividad empresarial, están las demandas sociales, que piden a las empresas tener en cuenta otros aspectos al valorar sus acciones; el impacto de las nuevas tecnologías, que provocan una mayor transparencia en 
Modelo de gestión integral para fortalecer la industria agroalimentaria venezolana Sánchez, Rebeca; Najul, María V.; Ferrara de Giner, Griselda y Ortega, Elizabeth

la información; el debate en el mundo académico sobre la naturaleza y el fin de la empresa; las propuestas de los organismos internacionales y de la sociedad civil; y la propia reflexión de la comunidad empresarial sobre su papel en el desarrollo de la sociedad (Fontrodona, 2005).

Un impulso importante a la incorporación de la $\mathrm{RSC}$ en la gestión integral de las empresas fue la iniciativa del Secretario de las Naciones Unidas, en el Foro Económico Mundial de Davos en 1999, quien propuso a los dirigentes empresariales sumarse a la iniciativa internacional Global Compact (Pacto Mundial), en cuyo marco las empresas colaborarían con las organizaciones de las NU, las organizaciones laborales y la sociedad civil, para promover principios sociales y ambientales de carácter universal.

El Pacto Mundial plantea tres planos de acción: derechos humanos, laborales y ambientales. El plano de los derechos humanos y laborales generalmente está sujeto al cumplimiento de estándares internacionalmente aceptados (Declaración Internacional de Derechos Humanos de Naciones Unidas, los cuatro principios fundamentales de la OIT y del Derecho del Trabajo, 1998) ${ }^{9}$. El plano ambiental, se refiere específicamente a la responsabilidad que compete a las empresas sobre las externalidades que genera su actividad productiva. Este plano abarca: la administración de recursos na- turales, control de la contaminación, manejo de desechos y el ciclo del producto.

Adicionalmente la RSC incluye una ampliación de la cobertura del concepto, que va más allá de la gestión de sus impactos ambientales: participación más activa de las empresas en problemas que se circunscriben a su entorno inmediato y que atañen a los empleados y a la comunidad en temas tales como salud y seguridad, saneamiento ambiental, acceso a agua potable, vivienda, alimentación y transporte, etc. Así mismo se estimula un rol empresarial más activo en problemas ambientales globales: cambio climático y deterioro de la biodiversidad (Núñez, 2003).

El cómo abordar la implementación de la RSC ha originado diversidad de guías, códigos de conducta, indicadores y procesos de planificación, provenientes de la discusión entre ONGs, gobiernos, sector académico, sector empresarial y trabajadores. Se reconoce, sin embargo, que existen cuatro elementos básicos que cualquier empresa debe considerar para lograr una exitosa responsabilidad social: 1) identificación de efectos sobre públicos interesados y consulta; 2) incorporación en la visión, misión y valores; 3 ) definición de políticas, procedimientos e indicadores; 4) gobernabilidad corporativa, responsabilidad para rendir cuentas y verificación.

La ética en las empresas no puede verse como un simple añadido, sino que afecta su estrategia de gestión, por lo que

9 Los cuatro principios laborales universalmente aceptados son: a) libertad de asociación y reconocimiento efectivo del derecho de negociación colectiva; b) eliminación de todas las formas de trabajo forzado u obligatorio; c) abolición efectiva del trabajo infantil y; d) eliminación de cualquier discriminación con respecto al empleo. 
requiere el compromiso de la alta dirección para el éxito de su implantación. Asimismo, debe apoyarse en una cultura organizativa, en la que el ejemplo y demostración por la vía de los hechos es imprescindible, evitando el doble discurso entre el quehacer diario y lo plasmado en el papel.

El debate sobre la responsabilidad social se mueve entre dos ámbitos: el conceptual y la aplicación práctica. Si bien los temas de ética y responsabilidad social tienen cierto carácter intangible, no pueden dejarse a la buena voluntad de las personas; pueden y deben gestionarse. Existen herramientas y procesos de gestión ${ }^{10}$ que permiten dotar a las empresas de medios para asegurar que los criterios sociales, medioambientales y éticos sean considerados en las decisiones diarias de sus empleados, del mismo modo que lo son los aspectos económicos.

Como apoyo al conocimiento y difusión de estas prácticas, existen interesantes ejemplos en empresas venezolanas, que han trabajado en estos temas, tales como las reportadas por Procter and Gamble de Venezuela, que resaltan el enfoque de sus actividades en un programa de bienestar integral de vanguardia orientado a su personal, que incluye desde gimnasio, masajes, exámenes médi- cos y asistencia nutricional dentro de la empresa, hasta comedor, ayuda psicológica y áreas deportivas para su personal. También manejan el concepto de tiempo flexible que permite, en función del cargo, trabajar un porcentaje del tiempo desde sus hogares.

Corporaciones bancarias como Banesco han invertido hasta $6 \%$ de sus utilidades en beneficios para sus trabajadores y familiares, brindan servicios de alimentación a bajo costo, servicio de guardería, se estimula la participación de género, ofrecen cabida a personas con discapacidades, aparte de actividades recreativas y culturales. En el Banco de Venezuela, para ascender se premia la realización de módulos de conocimiento establecidos en un plan de estudios de acuerdo al cargo, poseen el proyecto elearning, trabajan con un concepto de vida activa y saludable, el $59 \%$ de la plantilla está conformada por mujeres y ofrecen créditos a tasas blandas a los trabajadores, talleres vacacionales, pasantías, becas, entre otros beneficios ${ }^{11}$.

Así como estas experiencias de responsabilidad social empresarial hacia lo interno, empresas como la Electricidad de Caracas resaltan sus logros hacia lo externo, ofreciendo instrumentos de pago tipo tarjeta recargable, compatible

10 Algunos instrumentos son: Estándares, que son principios generales que reflejan los valores y objetivos de RSC, de carácter voluntario y no generan obligaciones, no requieren seguimiento y su alcance y profundidad varían según los temas. Códigos de Conducta, que ofrecen lineamientos más específicos para que las operaciones de las empresas cumplan con los principios de RSC. Indicadores son propuestos por la GRI para que las empresas puedan evaluar sus avances en materia de RSC (Correa et al., 2004).

11 Empresas cuidan el recurso más preciado: sus empleados. Artículo de prensa, El Nacional, Claudia Delgado Barrios, 9 de mayo de 2006. 
Modelo de gestión integral para fortalecer la industria agroalimentaria venezolana Sánchez, Rebeca; Najul, María V.; Ferrara de Giner, Griselda y Ortega, Elizabeth

con cajeros automáticos, permitiendo a personas que no poseen cuentas bancarias, pagar el servicio de manera fraccionada y hacer otros tipos de transferencia, lo que adicionalmente estimula al ahorro y una mejor administración del dinero ${ }^{12}$.

Otra experiencia relevante es el Proyecto Alcatraz, financiado por la firma Ron Santa Teresa, iniciativa que ha permitido la recuperación de jóvenes con problemas de conducta en los valles de Aragua, mediante su incorporación en seis proyectos de inversión comunitaria. Los grupos de jóvenes son puestos a prueba durante tres meses, en trabajos intensivos de siembra, formación en valores, práctica de rugby y labor comunitaria. Al final del lapso, se gradúa la promoción y se premia al graduado dándole trabajo formal con ingreso mensual o instrucción técnica en el Taller del Constructor Popular, que es otro de los seis proyectos de inversión comunitaria (González y Márquez, 2005). De esta manera han logrado canalizar la energía de estos jóvenes, transformados en "líderes del cambio", hacia proyectos beneficiosos para la comunidad, disminuyendo los dos principales problemas del municipio Revenga del Estado Aragua: desempleo e inseguridad, realzando la autoestima de los jóvenes del municipio, contribuyendo a la reducción del índice delictivo, mejorando las condiciones de vida del municipio y captando líderes de la comunidad con una nueva visión del municipio. Este estudio de caso ha sido seleccionado como modelo en materia de inversión so- cial empresarial y resultado ganador de varios premios nacionales e internacionales.

Para finalizar el análisis, es importante considerar que, en el caso de la industria de agroalimentos, el concepto de seguridad alimentaria incorpora un elemento condicionante a la responsabilidad social empresarial. En este contexto, las normas de calidad e inocuidad traspasan lo puramente técnico y sanitario y se convierten en un elemento de responsabilidad social para garantizar la seguridad alimentaria. La mayor concienciación de la opinión pública acerca de los peligros asociados a los alimentos, la preocupación por la amenaza a la salud pública que pueden suponer y una menor confianza en la capacidad de los sistemas vigentes de suministro de alimentos, son factores a considerar en la elaboración de la estrategia relativa a la cadena alimentaria.

\section{El modelo propuesto}

De lo discutido hasta este punto se desprende que, para alcanzar un desempeño exitoso y sustentable, la empresa requiere incorporar entre sus estrategias de gestión, elementos que le permitan, además de incrementar su eficiencia productiva, diferenciarse de sus competidores, para asegurar su permanencia en el mercado, ofreciendo responsable y oportunamente, productos de calidad e inocuidad inobjetables, respetando valores éticos y comprometida con sus trabajado-

12 Conectados con la comunidad. Artículo de prensa, TalCual, Carmen Victoria Méndez, 22 de mayo de 2006. 
res y con la sociedad en general, así como con la preservación del ambiente. Todo ello en el entendido de que la atención a factores tales como calidad, inocuidad, ambiente y seguridad industrial son compromisos ineludibles de la firma.

Alcanzar un desempeño con tales características requiere diseñar una estrategia que, sin olvidar la realidad de la organización y su entorno, facilite el avance hacia el logro de los estándares de competitividad señalados. Se propone entonces un modelo de gestión integral, cuya implantación contribuya a consolidar las bases para lograr un desempeño exitoso, en su concepción más amplia.

El modelo propuesto, esquematizado en el Diagrama 5, concibe a la organización en proceso de formación o en el correspondiente a una revisión profunda de su actuación.
El mismo se describe en los siguientes términos: la empresa, atendiendo a los valores éticos y de responsabilidad declarados en su política de gestión ${ }^{13}$, estructura sus componentes organizativos, tecnológicos y económicos, interactuando entre sí y concentrados inicialmente hacia el logro de una producción segura, así como en la valoración del talento humano con el que cuenta, la información que se genera y el aprendizaje obtenido de su actuación empresarial.

Los factores calidad, inocuidad, ambiente, seguridad y responsabilidad social se conciben, como aspectos incorporados a la cultura empresarial y a la organización como entidad dinámica, sometida a las presiones del entorno local e internacional, donde además de influir los cambios en la normativa de obligatorio cumplimiento o de adscripción voluntaria

\section{Diagrama 5 \\ Modelo Conceptual para la Gestión Integral en la Agroindustria Venezolana}

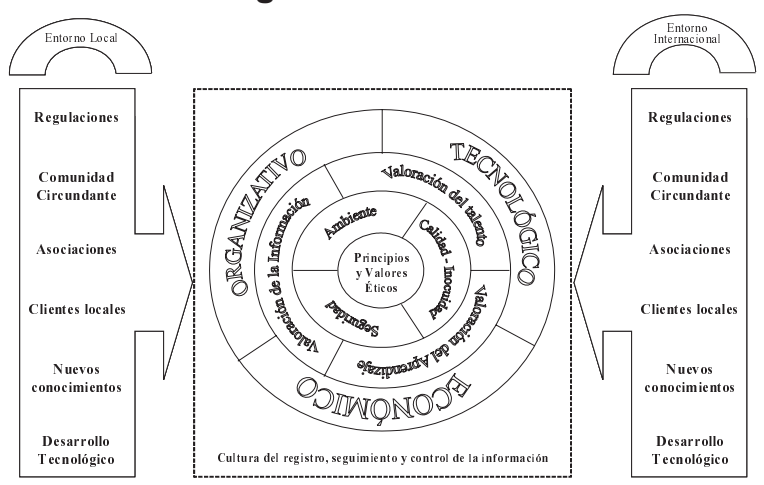

Fuente: Elaboración propia.

13 Cualquier decisión en materia de gestión debe responder a una declaración de política compartida por todos los integrantes de la organización. 
Modelo de gestión integral para fortalecer la industria agroalimentaria venezolana Sánchez, Rebeca; Najul, María V.; Ferrara de Giner, Griselda y Ortega, Elizabeth

a nivel local e internacional, las exigencias de los consumidores y otras instancias vinculadas, también lo hace el surgimiento de nuevos conocimientos y desarrollo tecnológico, tanto en su área de especialidad como en otras relacionadas.

En este concepto, la cultura del registro, seguimiento y evaluación de la información, generada tanto a lo interno como a lo externo de la firma, es de vital importancia, convirtiéndose en eje transversal en la actuación de la empresa. A este nivel, la firma estaría en capacidad de mostrar su desempeño y el mismo debería ser exitoso, sin embargo requiere su certificación. Para avanzar en este sentido, se propone complementar el modelo con una jerarquización de objetivos, en términos de demostración e incluso certificación de su desempeño, como se ilustra en la Figura 2.

Enfocarse al logro de la producción segura, constituye un paso firme para cumplir con las exigencias de las diferentes modalidades de certificación de cumplimiento de normas obligatorias y de adscripción voluntaria, desarrolladas para el apoyo a la gestión de los aspectos CISA. Esto puede facilitarse con un esfuerzo adicional de sistematización de la

Figura 2

\section{Jerarquización de objetivos en términos de certificación del desempeño}

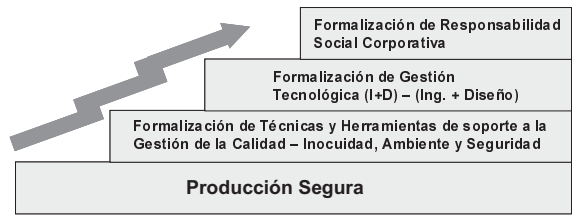

Fuente: Elaboración propia. información y adecuación a las exigencias de las normas.

Las actividades asociadas a la gestión tecnológica (investigación, desarrollo, ingeniería y diseño) y gestión del conocimiento, aun cuando se conciben incorporadas en la cultura de quienes tienen la responsabilidad de impulsar el desarrollo y crecimiento de la empresa, requieren de apoyo y fortalecimiento para su formalización, lo que apuntalará la generación de conocimientos y tecnología, útiles para el crecimiento integral y sustentable de la organización.

La actuación de la empresa, apegada a valores éticos y de responsabilidad social, debe asumirse en forma corporativa y reflejarse en acciones concretas, es decir, estableciendo directrices y lineamientos específicos, que permitan verificarlos.

En la medida que se incorporen todos los factores que caracterizan la firma, sus oportunidades y fortalezas, así como sus debilidades y amenazas, el modelo se convierte en una especie de código genético de la organización que le proporciona identidad propia y caminos para evolucionar satisfactoriamente, según ilustra el Diagrama 6.

\section{Conclusiones}

El análisis de los principales factores que han inducido cambios beneficiosos en el desempeño sustentable del sector empresarial -gestión de la calidad e inocuidad, seguridad de los trabajadores, ambiente, valoración del conocimiento, desarrollo de capacidades para la innovación tecnológica y responsabilidad social-, complementado con la determinación del grado de asociación entre 


\section{Diagrama 6 \\ Visión integral del Modelo Propuesto}

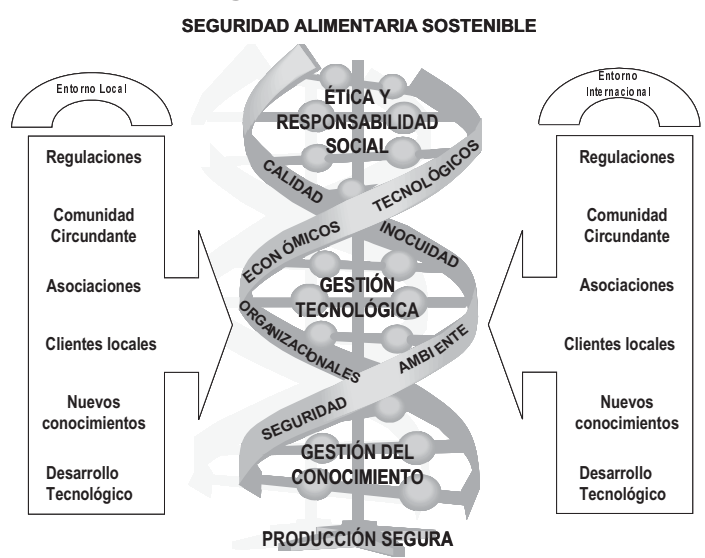

Fuente: Elaboración propia.

algunos indicadores de buen desempeño y aquellas acciones que reflejan la incorporación de tales factores en una muestra de 129 empresas pertenecientes al sector agroalimentario venezolano permitió la construcción de un modelo conceptual y de adopción progresiva, donde se introduce el concepto de producción segura como paso fundamental para la posterior incorporación de elementos que refuercen la capacidad de respuesta ante los permanentes cambios en el entorno, así como prácticas empresariales basadas en valores éticos y en el respeto hacia a las comunidades internas y externas. El modelo desarrollado, así como las estrategias para su implantación representan una propuesta que puede servir de apoyo o referencia a la gestión empresarial y las herramientas señaladas una manera para lograrla. Sin embargo, para la pequeña y mediana empresa podría significar una meta inalcanzable si no se facilitan mecanismos de cooperación en- tre ellas o con la gran empresa. En este aspecto, las asociaciones empresariales tienen un importante papel de capacitación e integración que cumplir, valiéndose del conocimiento de las fortalezas y debilidades de sus asociados y buscando las oportunidades de crecimiento de manera conjunta.

\section{Referencias Bibliográficas}

Asamblea Nacional de la República Bolivariana de Venezuela (2005). Ley Orgánica de Prevención, Condiciones y Medio Ambiente de Trabajo. Gaceta Oficial de la República Bolivariana de Venezuela, $N^{\circ} 38.236$, Caracas, Venezuela.

Comisión Económica para América Latina y El Caribe - CEPAL (1999). Industria y Medioambiente en México y Centroamérica. Un reto de supervivencia. Edición limitada de la Comisión Económica para América Latina y EI Caribe - CEPAL, LC/MEX/L.409, México. Pp 139.

Chavarría, Hugo. Sepúlveda Sergio (2001). Factores no económicos de la competitividad. Serie Cuadernos Técnicos 
Modelo de gestión integral para fortalecer la industria agroalimentaria venezolana

Sánchez, Rebeca; Najul, María V.; Ferrara de Giner, Griselda y Ortega, Elizabeth

Instituto Interamericano de Cooperación para la Agricultura IICA, $\mathrm{N}^{\circ}$ 18. San José de Costa Rica. Pp 44.

Chidiak, Martina y Murmis, María Rosa (2003). Competitividad sistémica. Componente: Gestión ambiental en la agroindustria, competitividad y sustentabilidad. ESTUDIO 1.EG.33.4. Oficina de la CEPAL-ONU, Buenos Aires. Pp 87.

Comisión del Codex Alimentarius (2005). Proposed draft principles for the application of traceability/product. Tracing in the context of food import and export inspection and Certification Systems. www: ftp://ftp.fao.org/codex/ccfics 14/ fc14 05e.pdf. 01/ 2006.

Correa, María Emilia, Flynn, Sharon, Alon Amit (2004). "Responsabilidad social corporativa en America Latina: una visión empresarial". Publicación CEPAL. Serie Ambiente y Desarrollo № 85 . División de Desarrollo Sostenible y Asentamientos Humanos. Santiago de Chile, Chile. Pp. 79.

De La Fuente, Angel (2003). Capital Humano y Crecimiento en la Economía del Conocimiento. Instituto de Análisis Económico (CSIC), Madrid. http://www. Navactiva.com/web/es/descargas/ pdf/amngm/capital_humano.pdf. pp45 01/07.

Escorsa Pere; Maspons Ramón; Cruz, Elicet (2001). Inteligencia Competitiva y Transferencia de Tecnologías: Reflexiones para el Desarrollo de la Relación Universidad - Empresa, Cataluña, España. http://www.oei.es/salactsi/pere2.pdf. 02/07. Pp. 16.

Fontrodona, Joan (2005). Gestión Integral de la RSE: El caso Novartis en España. Edita FORETICA. Documento en línea: www.foretica.es. 02/07.

Food and Agriculture Organization - FAO, (1996): Declaración de Roma sobre la Seguridad Alimentaria Mundial. Documento en línea: http://www.fao.
Org/documents/show cdr.asp?ur I file=/docrep/003/W3613S/W361 3S00.HTM. 02/07.

Freeman, Christopher (1998). La economía del cambio tecnológico. Artículo in extenso incluido en Fundación para la Innovación Tecnológica (2000): Economía de la Innovación. Las visiones de Ralph Landau y Christopher Freeman (2000). Documento en línea: http//www.cotec.es. 024/2007.

González, Rosa; Márquez, Patricia (2005). Las Iniciativas Sociales de Ron Santa Teresa. Social Enterprise Knowledge Network. SKS-045. Documento en línea: http//www.ruv.itesm.mx/portales/catedras_corporativas_cemex/ empresa/recursos/libro/Santa_Teresa_Caso_Docente_Oct_05.pdf. 01/07.

Herring, Jean (1992). The role of intelligence in formulating strategy, Journal of Business Strategy, Vol.13, Núm. 5, Pp. 10-12.

Iglesias, Daniel Humberto (2002). Competitividad de las PYMES Agroalimentarias. El Papel de la articulación entre los componentes del sistema agroalimentario. Serie Cuadernos Técnicos Instituto Interamericano de Cooperación para la Agricultura - IICA № 20. San José de Costa Rica. 85p.

Lovera, Julián Heberto (2006). "Sistema de registro, seguimiento y control de un proceso de producción de leche de larga duración". Trabajo Especial de Grado, Facultad de Ingeniería, Universidad Central de Venezuela, Caracas. Pp. 133

Mercado, Alexis; Testa, Pablo; Córdova, Karenia; Ortega, Elizabeth; Loreto, Dulce; Arispe, Ivelio.; Tapia, María Soledad; Najul, María Virginia; Ferrara Griselda; Sánchez, Rrebeca (2007). Aprendizaje tecnológico y gestión integral (tecnología, calidad y ambiente) en la industria agroalimentaria 
venezolana. Informe Final del Proyecto FONACIT. Caracas. Pp. 166.

Mercado, Alexis y Testa, Pablo Editores (2001): "Tecnología y Ambiente: El desafío competitivo de la industria química y petroquímica venezolana". Fundación Polar, Caracas. Pp. 373.

Miller, Stephen (2002). Competitive Intelligence - An Overview. Competitive Intelligence Magazine. Documento en línea: www.scip.org/Library/overview. $02 / 06$.

Ministerio de Sanidad y Asistencia Social (1996). Buenas Prácticas de Fabricación, Almacenamiento y Transporte de Alimentos para Consumo Humano. Gaceta Oficial de a República de Venezuela, № 36.081, Caracas.

Najul, María Virginia; Ortega, Elizabeth y Sánchez, Rebeca (2001). La Variable Ambiental en la Gestión Empresarial de la Industria Química y Petroquímica Venezolana, Capítulo 10 en: Tecnología y Ambiente: El desafío competitivo de la industria química y petroquímica venezolana. Mercado y Testa, editores. Fundación Polar, Caracas. Pp 211-238.

Núñez, Georgina (2003). "La Responsabilidad Social Corporativa en un marco de desarrollo sostenible". Publicación CEPAL. Serie Ambiente y Desarrollo No 72. División de Desarrollo Sostenible y Asentamientos Humanos. Chile. www.eclac.cl/id.asp?id=14904 - 28k. 03/07.

Organization fod Economic Cooperation and Development - OECD (2003). Organization fod Economic Cooperation and development - Overview OECED Sciency, Technology and Industry: Scoreboard 2003. Documento en línea http://www.oecd.org/boohshop. 03/07.

Palop, Fernando; Vicente, José María (1999). Vigilancia Tecnológica e Inteligencia
Competitiva: su potencial para la empresa española. Fundación COTEC, Documento en línea: http://www.cotec.es/ca/index.html. 06/07.

Portillo García-Pintos, Jesús (2002). El trípode calidad, prevención, medio ambiente. Una práctica ilustración de la gestión integral de los recursos. Revista Industria y Minería. № 348 junio 2002, Consejo Superior de Colegios Oficiales de Ingenieros de Minas de España. Www.mtas.es/insht/research/jpgp min.htm. 03/07.

Rothery, Brian (1996). ISO 14000 / ISO 9000. Panorama editorial, México. Pp. 290.

Roussel, Philip; Saad, Kamal; Erickson, Tamara J. (1991). "Tercera Generación de I + D”, Arthur D. Little, Inc. Editorial McGraw-Hill, Madrid. Pp. 259.

Sánchez, Rebeca; Najul, María Virginia y Loreto, Dulce (2001). El Marco Normativo Ambiental Venezolano, Capítulo 14 en Tecnología y Ambiente: El desafío competitivo de la industria química y petroquímica venezolana. Mercado y Testa, editores. Fundación Polar, Caracas. pp 299 - 318.

Society of Competitive Intelligence Profes SCIP (2001). Competitive Intelligence Proffesionals Salary Survey and Referente Guide on Analyst Job Descriptons. SCIP Publication 21001 Summary. Documento en línea http://www.scip.org/ci/saleec.asp. 04/07.

Testa, Pablo (2006). Índices de correlación de variables a partir de los datos recopilados en el estudio:"Aprendizaje tecnológico y gestión integral (tecnología, calidad y ambiente) en la industria agroalimentaria venezolana". En proceso de publicación. CENDES, UCV.

World Bank (2005). 2005 World Development Indicators. Documento en línea: http://devdata.worldbank.org/wdi/wdi 2005/Section. 01/07. 